\title{
A CRITICAL DISCOURSE ANALYSIS OF RHETORICAL DEVICES OF TRUMP'S AND MAY'S SPEECHES DURING THE PERIOD 2017 TO 2019
}

\author{
Hind Mohammed Sami, Asst. Prof. Bushra Nima Rashid (Ph.D) \\ University of Baghdad, \\ College of Education for Human Science-IbnRushd \\ Dept. of English
}

DOI: $10.37648 /$ ijrssh.v10i02.046

Received: 19 ${ }^{\text {th }}$ April, 2020; Accepted: 03rd May, 2020; Published: 23 ${ }^{\text {rd }}$ May, 2020

\begin{abstract}
This study tackles the use of Rhetorical Devices in the Presidential American and British speeches. As it is popular, these devices are most widely used in the literary works, and areless used in political speeches. Recently, the usage of such devices increased widely. This study investigates who are the politicians who use such devices, and manipulate them in order to seize the audience's attention in addition to convince them effectively.
\end{abstract}

\section{INTRODUCTION}

A brief history about the development of critical discourse analysis has been stated in this study.In addition, the conceptual tools for the analysis especially Burke's and Fairclough's model will be discussed and adopted to reach to the required conclusions and results. After the analysis, there will be some results which are either verified the hypotheses or rejected them.

The study is intended to search answers for the following questions;

1- What is the efficiency of rhetorical devices in presidential speeches especially between the U.S president and the British prime minister?

2. Does gender affect the quality of rhetorical styles usage?
3 . What is the amount and diversity of tropes in presidential speeches in 2017-2019?

The current study aims at:

1. Shedding the light on what kinds of rhetorical tropes American and British politicians prefer to employ in presidential speeches.

2. Identifying with a degree of precision the rhetorical devices which are responsible for variations noticed between American and British political speeches.

3. Investigating how far rhetorical tropes in American political speeches are similar or different to those in British ones concerning gender and culture. 
It is hypothesized that:

1. Presidential speeches in American and British are different according to gender, culture and state policy.

2. Rhetorical devices between American and British presidential speeches are dissimilar.

3. Ethos, Logos and Pathos strategies are used more in American presidential speeches than in the British ones.

The study is limited to:

1. Studying rhetorical devices from a critical discourse analysis point of view to some selected presidential speeches (American and British).

2. Creating an eclectic model for the analysis that has been adopted from: Burke's (1969) for the classification of rhetorical devices, and Fairclough's (1995) model for CDA.

3. Choosing the data is dependent on eclectic basis from (different speeches) and within the period of (2017- 2019) and for different occasions.

The data chosen are 30 presidential speeches, American and British. The researcher has chosen two different characters (male and female). The American data is illustrated by the president Donald Trump, while the British data is illustrated by the Prime Minister Theresa May. The 30 speeches have been chosen on different occasions and within the period of (2017-2019) .

\subsection{THEORETICAL AND CONCEPTUAL TOOLS}

In this section, a brief overview of the theories and approaches that are related in one way or another with the present study is introduced in this section.

\subsection{THE NATURE OF DISCOURSE ANALYSIS}

Discourse and discourse analysis as two linguistic concepts are used randomly among other concepts. Titscher et al, (2000: 13) as cited in (Bayram, 2010: 10), claim that discourse "integrates a whole palette of meanings" has involved a large area from linguistics, through the fields of sociology, philosophy and others. On the other hand, Bayram (ibid.: 23-40) also states that Fairclough (1989) has referred to the concept of discourse as being "the whole process of interaction of which a text is just a part". In this case, discourse has the major role in the process of communication. Indeed, discourse assists to express oneself through using words.

Literally, discourse as a linguistic concept is depicted as the formal speech which can be either a piece of writing or a discussion. In other words, discourse involves in both the spoken or/andwritten forms. Discourse sometimes has described as being language puts in use.(Schaffner,2009:158)

Cook (1992:14) refers to discourse as a language that is used in the process of interaction, while to search for what gives a discourse coherence is discourse analysis. Furthermore, Cook (ibid) also has explained that discourse analysis is used as a mean to examine how language elements, in their full textual, social, and psychological contexts turn to be meaningful and unified for their users. Moreover, Rymes (2008:12) (as cited in Mirzaee\&Hamidi (2012)) supposes that discourse is stated as "language-in-use." and discourse analysis, is how language-in use being affected by its context. In addition, Brown and Yule (1983:12) view that the term 'discourse analysis' has been used to describe various actions that are regarded as intersections of linguistic fields such as sociolinguistics, psycholinguistics, philosophical and computational linguistics, etc.

\subsection{WHAT IS CRITICAL DISCOURSE ANALYSIS}

Breeze (2011:493) has discussed that some linguists like Fairclough, Wodak and Meyer have announced that (Critical Discourse Analysis (hence forth CDA)as a sub discipline from discourse analysis, has been regarded as an independent field which has its own model, techniques, proposition as well as the structures of power.

Furthermore, Fairclough (1995:132) explains CDA as:

By CDA I mean discourse analysis which aims to systematically explore often opaque relationships of causality and determination between (a) discursive practices, events and texts, and (b) wider social and cultural structures, relations, and processes: to investigate

how such practices, events and texts arise out of and are ideologically shaped by relations of power and 
struggles over power, and to explore how the opacity of these relationships between discourse and society is itself a factor securing power and hegemony.(ibid) Whereas, Wodak and Meyer (2001:2) clarify CDA as:

It is concerned with analysing opaque as well as transparent structural relationships ofdominance, discrimination, power and control as manifested in language. It also aimsto investigate critically social inequality as it is expressed, signalled, constituted, and legitimized, and so on by language use

Language is viewed as being essential element in critical discourse analysis and other processes. In this case, Fairclough and Wodak (1997:15) point that 'language as social practice' and the 'context of language use' are important. In addition, a text is produced through the sociocultural environment and then consumed from CDA aspects. The below definition is quoted by Fairclough and Wodak (ibid):

CDA sees discourse - language use in speech and writing - as a form of 'social practice'. Describing discourse as social practice implies a dialectical relationship between a particular discursive event and the situation(s), institution(s) and social structure(s), which frame it. The discursive event is shaped by them, but it also shapes them.

Consequently, CDA, as Fairclough (1996: 287) defines it is like a perspective that is associated often with opaque connections that hold between language and some other aspects such as culture and society.

For Widdowson (2004:158), CDA is seen as a method whose target is ideological. It is devoted to the cases of social justice in addition to its aim to state and discuss utilization and the perversion of power. While Kress (1996:15) argues that CDA has a political schedule which intends to vary imbalanced distributions in modern societies such as economic, cultural and political goods. To achieve this purpose, it was to put a system of power disparities and then to discover its effects and workings throughout analyzing the cultural objects-texts. Furthermore, Bhatia et.al (2008:11) have clarified that CDA is emphasized basically on sociopolitical domination that includes aspects of social change and development, perversion of power, ideological imposition, and social inequality achieved by analyzing language as social action.

\subsection{CRITICAL DISCOURSE ANALYSIS : A BRIEF HISTORY}

Asthe linguist Van Dijk (2008: 85) has regarded CDA as discourse analysis development. CDA trace back to both social theory and systemic function linguistics that appeared in the beginning of 1970s.

Discourse is regarded as the totality of text (spoken/ written language), discourse practice (production, distribution and consumption of text) and social practice. Discourse is described by the context of occurrence of certain utterances like (political discourse, internet discourse and religious discourse, etc). So, CDA has been described as being a response to the epidemic formal modals especially of the 1960s which is DA. For example, DA has been explained by Van Dijk (ibid.) either as "a social" or "uncritical" since it has dealt with the devices of linguistic, grammatical cohesion, as well as the principles of semantics which connect each part into wholes. Meanwhile, CDA synchronizes with critical developments basically in psychology, sociolinguistics, in addition to other social sciences such as politics and philosophy, which can be traced back to the 1970s (Van Dijk, ibid.).

Blommaert (2005:27) claims that those socialists (Marx, Gramsci, Althusser, and Foucult), have a crucial influence on CDA's notions ,for instance, 'ideology', 'orders of discourse', 'hegemony', and others. While, nominalization, mood, transitivity, agency, and register have been regarded by Blommaert and Bulcaen (2000: 454) as analytical elements that are subsequent to systemic-functional analyses.

CDA, as a new scope of DA, has developed concurrently with other critical studies; in particular, social sciences. Van Dijk (1998: 17) opines CDA as a discipline which is associated with the processes of studying and analyzing written and spoken texts so as to expose the discursive sources of power, ascendancy, inequality and prejudice.

CDA has been differentiated from other forms of discourse analysis because of its critical nature. In fact, critical involves to go beyond analysis of the formal characteristics of discourse in order to state connections and causes that imply a discourse((Brinker et. al., 2014: 22).

Weiss and Wodak (2003:21) notice that CDA initially has substitutional labels which are "critical language awareness" or "critical language studies" and "critical 
linguistics" that seem to be used interchangeably with CDA. The linguists Wodak and Meyer (1996:31), for instance, "Critical Linguistics" (CL) and "Critical Discourse Analysis" (CDA) are always being used interchangeably, but the term CDA has been preferred ,recently, to refer to the theory which thendescribed as CL (Wodak and Meyer 2003: 14). They (ibid) also state that the central aspect of CDA is often associated with power as a basic component in social life.

In accordance with Rahimi\&Riasati (2011: 31), this field has attracted many linguists' attention since the 1980 s, crucially with the works of Fairclough, who is the British sociolinguist.

CDA is called critical because it has an ethical stance:

CDA practitioners typically take an ethical stance, one that draws attention to power imbalance, social inequalities, non-democratic practices, and otherinjustices in hopes of spurring readers to corrective action --- CDA not only describes unfair social --- practices but it is explicitly critical of them(Huckin 1995: 96)

\subsection{CRITICAL DISCOURSE ANALYSIS: MAJOR AIMS}

There are many aims for CDA, but only some of them are going to be discussed below, since the excluded aims have no relation with the topic under investigation:

1. For the concept of CDA, the relation between language and power is essential. So, language is regarded as social practice. (Wodak and Meyer, 2001:1-2).

2. (One of the targets of CDA is to tackle some terms such as cultural phenomena, the process of change, and the social discursive dimension. Politics, economy, racism, mass communication and identity are areas that have been covered by CDA) (Jorgensen and Philips, 2002:61).

3. Dealing obviously with the connections such as social practices, and structures in addition to discursive practices is one of the tents of CDA, (Fairclough, 1993:135).
4. CDA deals with studies from a critical point of view such as the relation between language and society (Hart, 2010:13). Whereas, Batstone (1995:198-199) has demonstrated that one of the attempts of CDA is to make opaque texts understandable to common people.

5. Stating and removing manipulation and ideology from texts is one of the tasks of CDA that are hidden from ordinary people, (Fowler, 1991:12).

6. CDA has been described by Hart (2010: 5) as having the best tools for showing the public instances of manipulation and ideology that are notclear to readers. Therefore, they supply readers with a recent critical awareness.

\subsection{CRITICAL DISCOURSE ANALYSIS : MAJOR APPROACHES}

CDA deals mainly with different methodological approaches that are utilized within different collections of data, (Weiss and Wodak, 2003:12). These approaches can be identified as: Critical Language Approach, Socio-Cognitive Approach, Discourse Historical Approach, and Socio-Cognitive Approach (Hart, 2010:14). Fairclough and Wodak (1997:271-80) have summarized the essential tenets of CDA as follows:

1. (CDA has been used for addressing the social problems).

2. (Discourse is seen as a form of social action).

3. (Discourse can also do the ideological work).

4. (Power relations are described as discursive one).

5. Society and culture can be constituted by discourse.

6. Discourse is regarded as a historical event. 
7. The linkage between both text and society is interposed

Fairclough's Socio-Cultural Approach is similar to the functional analysis of Halliday (1994, 2004, 2014), Fairclough's system of discourse analysis has three dimensions, since discourse is seen simultaneously as: (i) a text (spoken or written, including visual images), (ii) a discourse practice production, consumption and distribution of the text, and (iii) a socio cultural practice. Subsequently, Fairclough provides a three-dimensional framework for the analysis of text and discourse: (a) the linguistic description of the formal properties of the text; (b) the interpretation of the relationship between the discursive processes/interaction and the text, and finally, (c) the explanation of the relationship between discourse and social and cultural reality.

The second approach is called Socio-Cognitive Approach. In accordance with Fairclough's critical approach, the Socio-Cognitive Approach put forth by Van Dijk perceives discourse as a form of social practice. However, it does not focus on discursive practice. Van Dijk rather concentrates on social cognition as the mediating part between text and society. He claims that CDA needs to account for the various forms of social cognitions that are shared by the social collectivities (groups, organizations and institutions) (Van Dijk, 2001). Social cognitions, he states, are "socially shared representations of societal arrangements, groups and relations, as well as mental operations such as interpretation, thinking and arguing, inferencing and learning" (Van Dijk, 1993, p.257). Van Dijk further identifies two levels of (discourse) analysis: macro vs. micro. Language use, discourse, verbal interaction, and communication determine are the micro level of social order, while the macro level refers to power, dominance and inequality between social groups (Van Dijk, 2003).

As the third approach isaDiscourse Historical Approach, the linguist Blommaert (2005:28) mentions that Wodak and her followers have established a discourse historical approach that is used to examine the history of phrases and sentences.

This Discourse Historical Approach is emphasized mainly on analyzing theways in which discourse changed over the time,(Forchtner, 2011:2).According to the linguists Wodak and Ludwig(1999:12-13), discourse historical approach implies three things:

1. Discourses are not free from power and ideology.

2. Discourses are historical. They are related to other communicative events which have happened.

3. Background knowledge and information and the position of individuals can give different interpretations to the same communicative event.

The fourth approach a Socio-cognitive Approach (henceforth SCA) that has created by Van Dijk (1995) andis used to connect simultaneously

Van Dijk (1995:18) points out that social cognition is "The system of mental representations and processes of group members". Moreover, Van Dijk (1993b:280) explains that in order to understand how texts can be constructed socially, textual structures should be linked to social cognition, and social cognition to social structures. The SCA is briefly epitomized in figure (1) below: 
Social Cognition

(Cognitive Structure)

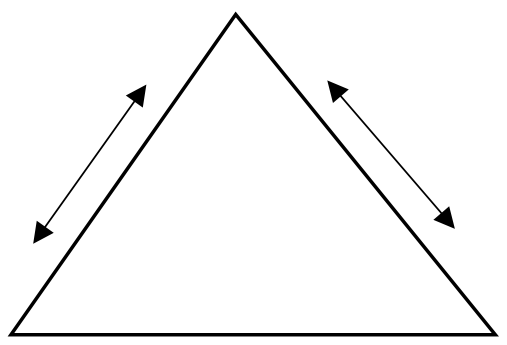

Social structure Textual structure

Figure 1: Textual-Cognitive-Social Structure Triangle

\subsection{POLITICAL SPEECHES}

Basically, language is the main aspect of communication and interaction which is considered as a vehicle of communication. Furthermore, speech is the essential focus of that vehicle which is doneby a given individual on a given situation and occasion. Thus, speech is the usage of language done by one person (for example a politician) in a particular position or situation. A politician is the one who is responsible for his / her speech, who is described as (the sovereign master). In fact, speeches depend on the way that politician uses to achieve his/her message as how or what to be said. In most of cases, he/ she may move from ordinary usage to the evolved one.

Political speeches have been defined by Collins (2002: 1) as "the deliberate oratory in which there is an emphasis on the actions that should be taken by the polis." This kind of speeches are based on the opinion that the rejection and support of a specific course of action essentially depend on whatever speeches are being either appropriate (acceptable) or not, to reach the desirable results that are intended by the action. Speeches of this sort are connected with matters of common interests. The emphasis, here, is to shed the light on the right and effective usage of words done by a dominant speaker. In addition, words can be used as a dangerous weapons in the realm of public opinion.

Price (2000: 343) has mentioned that political speeches are identified by having power. Further, power plays a crucial role in politics, on the other hand, the speakers attempt to have control over their hearers through authority that is ascribed to them. In this case, it is important for the speaker to get his/her audience's attention by applying the language effectively and convincingly. The basic concern of politician is to shed the light on conclusive concerns and affairs of his/her community and to attempt the best in order to persuade hearers that his/her thoughts are to serve their benefits.

\subsection{RHETORICAL DEVICES: TYPE AND STYLE}

Regarding Shen (2006), he points out that rhetorical device is also called a trope, or a figure of speech, or a rhetorical figure. It is composed of series of words that are derived from the exact meaning of the words, or from the familiar usage of words. In this sense, they are called 'floresrhetoricae' which means 'the flowers of rhetoric'. According to Mcquarrie\& Phillips (2014:26), rhetorical figures seize the audience's attention in order to understand the message. The study of rhetorical figures, over the years, have been a subject of interest in different fields like poetry, traditional rhetoric, and more recently cognitive linguistics and psychology, (Shen, 2006:18). Consequently, figurative language forms are divided into two main groups: schemes; in which the researcher is going to give a brief information about them and not to dig deep on them, since they are out of the range of this study, nevertheless, information about schemes concerning types and levels will be mentioned; and tropes which are specified to be analyzed in this study. Consequently, rhetorical schemes are dealing with describing three levels in the text: phonological schemes (the arrangement of individual sounds), morphological schemes (the arrangement of words), and syntactical schemes (sentence structure). Whereas rhetorical tropes deal with 
semantic figures (a deviation from the common appeals to the significance of a word or a phrase), and pragmatic figures (including specific appeals to the audience). Schemes and tropes are described as below:

A. Schemes with level of individual sounds include (alliteration, Assonance, consonance, onomatopoeia).

- Schemes with word-level include (reduplication, anaphora, climax, epistrophe, epanaleosis, homonym, polyptoton, portmanteau, symploce, synonym, tautology).

- Schemes with sentence- level include (aposiopesis, asyndeton, chiasmus, ellipsis, hyperbaton, hypotaxis, inversion, parallelism, parataxis, polysyndeton, reddition, and zeugma).

B. Tropes include (antithesis, apostrophe, euphemism, hyperbole, irony, metaphor, metonymy, oxymoron, paradox, paronomasia, pejorative, periphrasis, personification, simile, synesthesia, synecdoche, understatement).

\subsection{DATA COLLECTION}

The data chosen are 30 presidential speeches, American and British.The researcher has chosen two different characters (male and female). The American data is illustrated by the president Donald Trump, while the British data is illustrated by the Prime Minister Theresa May. The 30 speeches have been chosen on different occasions and within the period of (2017-2019) .

\subsection{DATA ANALYSIS}

The researcher is going to analyze rhetorical devices according to Burke's model (1969) and Fairclough's model (1995). The researcher adopts Burke's model because it tackles the identification of tropes in his Rhetorical Theory. He divides rhetorical devices into tropes. These tropes are categorized into (metaphor, metonymy, synecdoche and irony). Moreover, the researcher adopts Fairclough's model to analyze the data according to three dimensions which are: 1) description of textual analysis. 2) Interpretation of production and reception. 3) Explanation of social conditions that affect production and reception; to analyze the data from a critical discourse analysis point of view.

A comparison between Trumps' and May's manipulation of the four rhetorical maneuvers has disclosed these devices equally employed by those presidents; they differ only in respect to synecdoche and irony, this can be shown through the following analysis.

The analysis of the 15 chosen political speeches of Trump has revealed that Trump resorts to the use of different rhetorical devices to attain various purposes associated with his governmental administration. The four assigned figurative tropes (metaphor, metonymy, synecdoche and irony) have been differently distributed, having different percentages. Table 5.1 depicts the frequencies and rates of these figures of speech as utilized in Trump's speeches:

\section{Table 5-1 : Trump's Use of Rhetorical Tropes}

\begin{tabular}{l|llll} 
No. & Rhetorical & Trope & Frequency & Percentage \\
\hline 1. & Metaphor & 7 & $\% 46.66$ \\
2. & Metonymy & 3 & $\% 20$ \\
3. & Synecdoche & 3 & $\% 20$ \\
4. & Irony & 2 & $\% 13.33$
\end{tabular}


This table shows that Trump mostly uses metaphor 7 times with a rate of $46.66 \%$ and least irony with a frequency of 2 and a percentage of $13.33 \%$. Of course, there are specific reasons behind Trump's manipulation of these devices. Perhaps, metaphor offers him more variety of uses as it enables him to give solid picture and provide him more representing images of the ideas associated with his intentions. He exploits metonymy and synecdoche equally 3 times having the rate of $20 \%$ each. By the two devices, Trump uses part-whole or vice versa relations to replace a less wide-ranging term for a more wide-ranging term or the opposite. That is, he can direct his philosophies in a more obvious and pictorial method.

Irony is manipulated in Trump's speeches to express various purposes, e.g. hostility, protection, amusement and to reflect a constructive function in connecting with his addressees. It indirectly contributes to producingpolitical speeches more impressive and satisfactory, in other words, ironic expressions and phrases help Trump to more eloquently manipulate public attitudes and opinions more effectively; in return, he can win support from his audience.

The percentages of the use of the four rhetorical devices by Trump can be more illustrated in Figure5-1.

\section{RHETORICAL TROPES}

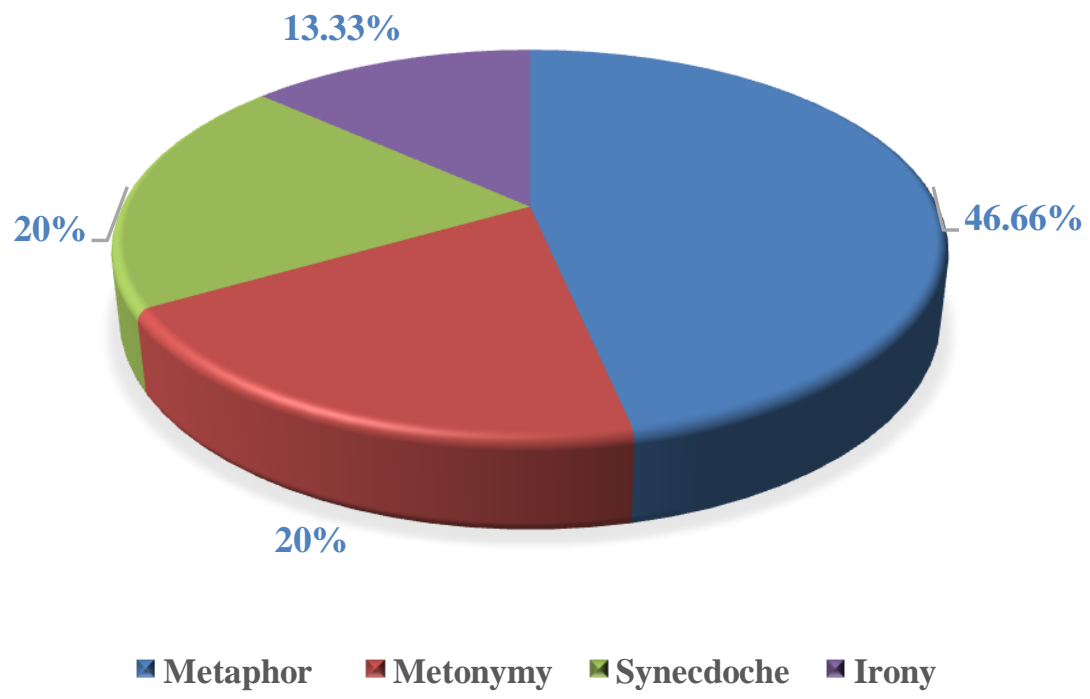

\section{Figure 5-1: Trump's Use of Rhetorical Tropes}

All in all, these devices, if appropriately applied, can stimulate the audience to construct confidence in Trump and endeavor for realization of Americans' dreams and intents. Rhetorical devicescan help him to better attract the Americans' attention and further make his words and expressions more powerful and convincing.

In case of the rhetorical analysis of the 15 selected political speeches of May has shown that she has recourse to the manipulation of various rhetorical devices to realize various functions linked to her governmental agenda and policy. Metaphor, metonymy, synecdoche and irony have been variously disseminated with various ratios. Table5.2 portrays the number of occurrences of each tool besides its percentages. 
Table Error! No text of specified style in document.-2: May's Use of Rhetorical Tropes

\begin{tabular}{|c|c|c|c|}
\hline No. & Rhetorical Tropes & Frequency & Percentage \\
\hline 1. & Metaphor & 7 & $\% 46.66$ \\
\hline 2. & Metonymy & 3 & $\% 20$ \\
\hline 3. & Synecdoche & 4 & $\% 26.66$ \\
\hline \multirow[t]{2}{*}{4.} & Irony & 1 & $\% 6.66$ \\
\hline & Total & 15 & $\% 100$ \\
\hline
\end{tabular}

It is clear from table 5-2that Maymostly uses metaphor7 times with a percentage of $\% 46.66$ and least irony with a frequency of 1 and a percentage of $\%$ 6.66. Metaphor bids her more variability of styles as it allows her to build more solid images and provides herwith obvious ideas and views contributing to attaining her goals.

In the second place, she utilizes synecdoche 4 times having the rate of $\% 26.66$. The idea of part-whole or vice versa helps her to replace a less comprehensive term for a more comprehensive one or the opposite. Metonymy, as a substitutable relation, can also be observed in the data with a frequency of 3 times, having a rate of $\% 20$. That is, she can convey herideologies and intentions in a more noticeable and illustrative way.
The idea of ridiculing others and things (irony) is least deployed in May'sspeeches, yet irony is employed to reflect various functions, e.g. aggression, security, delight and to replicate a positive role in getting involved with May's recipients. It ultimately adds more satisfaction and power to the produced message. She can, with the help of irony, reflect her inner feelings and thoughts to the public; she can more attract her audience with satirical manipulation and win their support and sustenance. All these four figurative agencies can be exploited to help Mayto attain her governmental and administrative responsibilities and duties.

The percentages of the manipulation of the four figurative devices (metaphor, metonymy, synecdoche and irony) can be more elucidated in Figure 5-2 


\section{RHETORICAL TROPES}

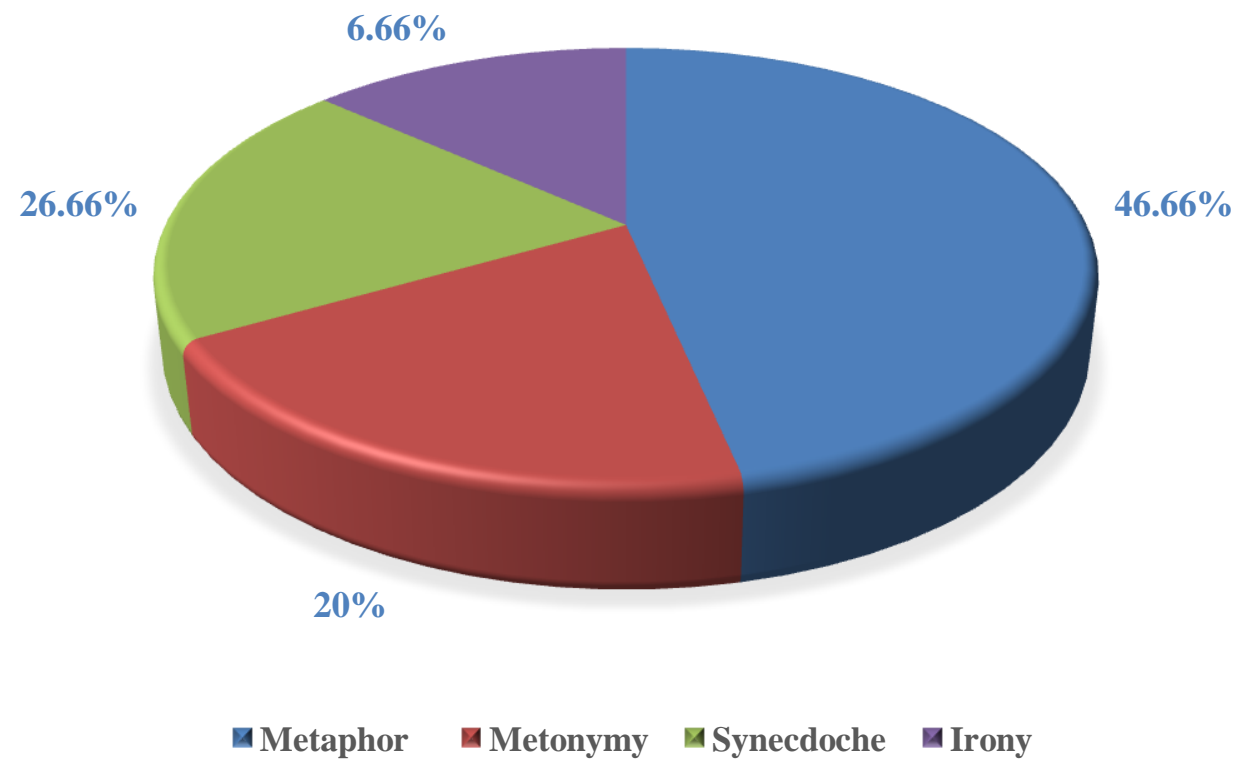

Figure Error! No text of specified style in document.-2: May's Use of Rhetorical tropes

\subsection{CONCLUSION}

The present study has led to the following conclusions:

1. Using these four rhetorical devices by both presidents Trump and May in order to help them to attain their governmental; administrative responsibilities and duties. To have power and authority over others.

2. Metaphor device is the most occurredelement among others. The reasonbehind using it by both presidents, is that, to build solid image about their character; get clear ideas and gain their aims.

3. The irony device is used by both presidents to deliver a massage in an indirect way

\section{REFERENCES}

Blommaert,J.2005. Discourse. Cambridge: CUP.

Fairclough N: Critical Discourse Analysis: The Critical Study of Language. London and New York: Longman; 1989.

Fairclough N: Critical Discourse Analysis: The Critical Study of Language.

London and York: Longman; 1995.

Fairclough, N. L. 1995. Critical Discourse Analysis: Papers in the Critical

Study of Language. London: Longman

Fairclough, N. L. 1996. Conversationalisation of public discourse and the authority of the consumer. In N. Abercrombie, R. Keat\& N. Whiteley (eds). The Authority of the Consumer. London: Routledge.

Van Dijk, T.A. (1993). Text and context: Explorations in the semantics and Pragmatics of Discourse. London: Longman Group Ltd. 
Van Dijk, T. A. (1995). Ideology and discourse analysis. Journal of Political Ideologies, 11 (2), 115-140.

Van Dijk, Teun van. 1997. The study of Discourse. In: Giles, H.\& W.P. Robinson (Eds.). Discourse as Structure and Process. Vol.1, Sage: London.pp.1-34.

Van Dijk, T. A. 1998 . Communicating racism: Ethnic prejudice in thought and talk. Newbury Park, CA: Sage Publications. van Dijk, T. A. 2008. Racism and the press. London: Routledge

McQuarrie, E. F.,\& Phillips B. J. (2014). Go Figure! New Directions in Advertising Rhetoric. London, UK: Routledge.

Leith, S. (2011). You Talkin' To Me? : Rhetoric from Aristotle to Obama. London, UK: Profile.

Charteris-Black, J. (2011). Politicians and Rhetoric: The persuasive power of metaphor. London, UK: Palgrave Macmillan. 